Review

\title{
Recent Advances in the Application of Metabolomics to Studies of Biogenic Volatile Organic Compounds (BVOC) Produced by Plant
}

\section{Yoko Iijima}

Department of Nutrition and Life Science, Kanagawa Institute of Technology, 1030 Shimo-ogino, Atsugi, Kanagawa 243-0292, Japan; E-Mail: iijima@bio.kanagawa-it.ac.jp; Tel.: +81-46-206-0209; Fax: +81-46-291-3345

Received: 18 May 2014; in revised form: 12 August 2014 / Accepted: 13 August 2014 / Published: 21 August 2014

\begin{abstract}
In many plants, biogenic volatile organic compounds (BVOCs) are produced as specialized metabolites that contribute to the characteristics of each plant. The varieties and composition of BVOCs are chemically diverse by plant species and the circumstances in which the plants grow, and also influenced by herbivory damage and pathogen infection. Plant-produced BVOCs are receptive to many organisms, from microorganisms to human, as both airborne attractants and repellants. In addition, it is known that some BVOCs act as signals to prime a plant for the defense response in plant-to-plant communications. The compositional profiles of BVOCs can, thus, have profound influences in the physiological and ecological aspects of living organisms. Apart from that, some of them are commercially valuable as aroma/flavor compounds for human. Metabolomic technologies have recently revealed new insights in biological systems through metabolic dynamics. Here, the recent advances in metabolomics technologies focusing on plant-produced BVOC analyses are overviewed. Their application markedly improves our knowledge of the role of BVOCs in chemosystematics, ecological influences, and aroma research, as well as being useful to prove the biosynthetic mechanisms of BVOCs.
\end{abstract}

Keywords: plant-produced biogenic volatile organic compounds; BVOC; metabolomics; aroma compounds; herbivore-induced volatiles; GC-MS; LC-MS 


\section{Introduction}

Biogenic volatile organic compounds (BVOCs) are produced and emitted from various organisms [1]. The total amount of BVOCs emitted globally to the atmosphere is estimated to exceed $1 \mathrm{Pg}$ per year [2]. These BVOCs include mainly plant-produced BVOCs, isoprene (44\%), monoterpenes (11\%), and other oxygenated carbon compounds, such as herbivore-induced volatiles and green leaf volatiles $(22.5 \%)[2,3]$. Their emission is easily affected by various abiotic global factors, UV strength, contents of ozone and $\mathrm{CO}_{2}$, drought conditions, eutrophication conditions, and warming [4]. The structures of BVOCs are complicated and chemically diverse, and more than 1700 volatile metabolites emitted from plant have been identified [5]. In many cases, the varieties of plant-produced BVOCs depend on the plant species, distinctive parts of the plants, or the circumstances under which the plants are growing [5-8]. The ecological roles of plant-produced BVOCs have been studied, and their roles are now known to include functions as defensive or attractive signals in interactions between plants and herbivores, pathogens, pollinators, and parasitoids, and more, the interactions between plants to plants by BVOCs are also observed [9-14]. The results of these studies indicate that the emission of BVOCs by plants is a useful communication tool. A particularly interesting point is that the structures of BVOCs that are synthesized for the above-mentioned interactions are sometimes unexpected and did not exist in the plants' original condition (Table 1).

The BVOCs that are perceptible to humans are important as aroma and/or flavor compounds [15] (Table 1). Essential oils, which are concentrated cocktails of BVOCs obtained by distilled water or solvent extraction from various aromatic plants, have been produced since ancient times. The aroma strengths and characteristics of essential oils are determined by the profiles of the composed aroma compounds, which vary by genotypes and cultivation conditions [16]. Some aroma compounds show beneficial functions, such as antioxidant and antimicrobial activities, contributing to the compounds' usefulness in food and cosmetics [17-21]. The composition of aroma compounds is thus a key factor in evaluations of the qualities of essential oils and agricultural products, such as flowers, vegetables, fruits, and herbs.

The common chemical properties of most VOCs are small molecules (up to $250 \mathrm{Da}$ of molecular weight), and easy to be gaseous at ambient temperature, although some VOCs, such as ethanol and acetic acid, are soluble in water. The extraction and analysis methods used for VOCs are unique but may be matured in comparison to those for non-volatile compounds. VOC research, in the field of flavor/flagrance chemistry, has been conducted for many years, and the structures of many VOCs have been identified by synthetic chemical techniques. For example, standard technologies for VOC analyses are gas chromatography (GC) equipped with a flame ionization detector (GC-FID) or mass spectrometry (GC-MS). Many types of GC columns to separate various VOCs are available. In particular, the mass spectral databases for VOCs are better established compared to other natural non-volatile organic compounds; more than 600,000 compounds are searchable in mass spectrum libraries [22]. Regarding data analysis, chemometrics, a basic methodology for metabolomics, has been already accepted in the flavor chemistry field. Chemometrics has been used in evaluations of the aroma profiles of samples and in the differentiation of varieties and cultivation sites of materials and essential oils [23-28].

Metabolomics uses analytical methods to elucidate various biochemical events and dynamics in biological systems, based on the comprehensive characterization of the small-molecule metabolites [29,30]. 
This is achieved by systematically collecting multiple metabolic profiles and analyzing them comprehensively and simultaneously [31,32]. Metabolomics for volatile metabolites differs from flavor chemical analyses in that metabolomics emphasizes more biological aspects-especially physiological and environmental effects - in or by the synthesis of volatiles in plants. Metabolomics also examines the relationship between the synthesis of volatiles and their genetic backgrounds, and the metabolic networks between volatiles and non-volatile metabolites [1,33]. Thus, the metabolomics approach specifically for volatiles has recently been named "volatile metabolomics" or "volatilomics" [34,35]. Here, we introduce recently developed metabolomics techniques concerning BVOCs and their applications, focusing on the elucidation of volatile synthesis and its relationship to ecological and physiological events in plants.

Table 1. Main groups of plant-produced biogenic volatile organic compounds (BVOCs) and their functional characteristics.

\begin{tabular}{|c|c|c|c|}
\hline $\begin{array}{c}\text { Compound } \\
\text { group }\end{array}$ & Typical BVOCs & $\begin{array}{c}\text { Precursors } \\
\text { (derived from) }\end{array}$ & Functional characteristics \\
\hline Isoprenoids & Isoprene & IDP & $\begin{array}{l}\text { Tolerance to sunlight- induced } \\
\text { heating }\end{array}$ \\
\hline Monoterpenes & $\begin{array}{l}\beta \text {-Ocimene, } \beta \text {-Myrcene } \\
\alpha \text { - } / \beta \text {-Pinene, Limonene, } \\
\text { Linalool, Geraniol }\end{array}$ & GDP & $\begin{array}{l}\text { Harbivore-induced signal, } \\
\text { Attractant to pollinator, } \\
\text { Fragrance }\end{array}$ \\
\hline Sesquiterpenes & $\begin{array}{l}\beta \text {-Caryophyllene, } \\
\beta \text {-Farnesene, Farnesol } \\
\text { Nerolidol }\end{array}$ & FDP & $\begin{array}{l}\text { Harbivore-induced signal, } \\
\text { Antimicrobial activity }\end{array}$ \\
\hline Homoterpenes & $\begin{array}{l}\text { TMTT } \\
\text { DMNT }\end{array}$ & $\begin{array}{l}(E, E) \text {-Geranyllinalool } \\
(E) \text {-Nerolidol }\end{array}$ & Harbivore-induced signal \\
\hline Phenylpropenes & Eugenol, Methylchavicol & Phenylalanine & $\begin{array}{l}\text { Aroma, Antioxidative activity, } \\
\text { Antimicrobial activity }\end{array}$ \\
\hline Benzenoids & Phenylethanol, Vanillin & $\begin{array}{l}\text { Phenylalanine } \\
\text { Phenylalanine/ } \\
\text { Isochorismate }\end{array}$ & $\begin{array}{l}\text { Aroma, Flagrance } \\
\text { Aroma, Harbivore-induced } \\
\text { signal }\end{array}$ \\
\hline Lipid derivatives & $\begin{array}{l}\text { Hexanal, Hexenals, Hexanol, } \\
\text { Hexenols, (Z)-3-Hexenyl acetate } \\
\text { Methyl jasmonate }\end{array}$ & Fatty acids & $\begin{array}{l}\text { Stress, damage, and } \\
\text { herbivore-induced signal, } \\
\text { Pathogen resistance }\end{array}$ \\
\hline $\begin{array}{l}\text { Aliphatic amino } \\
\text { acid/lipid } \\
\text { derivatives }\end{array}$ & $\begin{array}{l}\text { Isomyl acetate, Isomyl alcohol } \\
\text { Hexyl hexanoate }\end{array}$ & $\begin{array}{l}\text { Leucine, Isoleucine } \\
\text { Acyl CoA }\end{array}$ & Fruit aroma \\
\hline S,N-containing & Disulfides, Trisulfides & $\begin{array}{l}\text { Glucosinolates } \\
S \text {-alk(en)yl cysteine } \\
\text { sulphoxides }\end{array}$ & $\begin{array}{l}\text { Hervibore-induced signal, } \\
\text { Antimicrobial activity, Flavor }\end{array}$ \\
\hline
\end{tabular}

DMNT: 4,8-dimethylnona-1,3,7-triene; FDP: Farnesyl diphosphate; GDP: Geranyl diphosphate; IDP: Isopentenyl diphosphate; TMTT: 4,8,12-trimethyltrideca-1,3,7,11-tetraene. 


\section{The Procedures Used for Collecting and Extracting Plant-Produced BVOCs in Metabolome Analysis}

Volatile synthesis in plants is known to be involved in both biotic and abiotic factors [33]. BVOCs can be (1) emitted by intact plants to the atmosphere; (2) stored in specialized tissues; and (3) synthesized after the disruption of tissues and cells. The procedures used to collect BVOCs are chosen in accord with the purpose of research, usually either by capturing one or more BVOCs from headspace gas or by extracting them with an organic solvent [36]. However, we have to recognize that the compositional profiles and concentration of BVOCs are differently provided by collecting procedures. Furthermore, some artifacts might be included in the BVOCs extracts from both procedures, because many of the volatiles are reactive.

Headspace gas includes, for instance, emitted volatiles, such as flower scent and isoprene from trees, and the increasing aroma from ripening fruits, such as strawberry (Fragaria $\times$ ananassa) and melon (Cucumis melo L.). Synthesized BVOCs can freely cross the cell membrane and are, thus, released to the atmosphere [8,37]. Trapping headspace gas from plant samples is effective to obtain BVOCs without damage to the plants. Two types of methods, static and dynamic headspace sampling, are widely used for the collection of BVOCs [22,38] (Figure 1).

Static headspace sampling is more passive and classical than dynamic headspace, however, less efficient for trapping of BVOCs, since they are diluted in the chamber. Static headspace sampling is usually performed with solid-phase microextraction (SPME) fibers in the small volume vial (Figure 1), being popular for fruit volatile analysis. The advantage of this technique is that more vaporized metabolites are detected sensitively. Several types of absorbents for SPME, which are chemically different in polarity from each other are available to collect various BVOCs. The absorbed BVOCs are also thermally desorbed with ease at the injection port of a GC instrument. The advantages of this method are that it sensitively detects larger numbers of volatile and smaller molecule compounds without loss, and also can reduce the damage to GC-MS filaments. Automated SPME-GC under robotic control is available and allows high-throughput analyses with good reproducibility. SPME methods are thus widely used for metabolomics data collection by GC-MS. However, the extraction efficiencies of each compound differ by the SPME fiber used [39,40]. It is, thus, necessary to keep in mind that an SPME profile does not always show the real composition of emitted volatiles. Divinylbenzene/carboxen/poly(dimethylsiloxane) fibers were recently reported to be suitable for metabolomics studies as they provide the optimum extraction coverage and sensitivity for the widest range of analytes [40]. Since the compositional profiles of BVOCs are influenced by temperature, humidity, and their trapping period, the optimal condition for each plant sample must be carefully set up. To increase the capacity of VOC absorption, stir bar sorptive extraction (SBSE) and monolithic material sorptive extraction (MMSE) are also used for analyses of VOCs [41-43]. The surface area of SBSE and MMSE is larger than that of SPME fibers, enabling the adsorption of more VOCs compared to SPME. Thermal desorption can be used to perform the direct introduction of VOCs to a GC-MS system, although an additional thermal desorption unit is needed [44].

The dynamic headspace sampling technique is usually performed under air circulation by a flow through the system [38,45] (Figure 1b). The plant sample is put in an enclosed container with air-in and air-out valves. The outside/ambient air is made to constantly flow through the container by a 
circulation pump and vacuum pump, and BVOCs are collected by an absorbent trap connected to the output valve for the vacuum pump. As the absorbent, proapak-Q resin and Tenax ${ }^{\circledR}$ resin are popular, and the absorbed BVOCs are extracted with a solvent such as dichloromethane, acetone, or diethyl ether [22]. Alternatively, thermal desorption is also acceptable for absorbent, and sometimes SPME method is used [44]. Furthermore, recent advances in volatile analysis enabled to detect BVOCs directly by proton transfer reaction-mass spectrometry (PTR-MS) (Figure 1b). The advantage of dynamic headspace analysis is that concentrated BVOCs are obtained under ambient conditions, because compositional changes in oxygen and carbon dioxide are avoided, and long-term experiments are possible with this technique. The dynamic headspace sampling technique is thus frequently used for the elucidation of volatile synthesis directly affected by environmental events, such as flowering, herbivore infestation, and other biotic or abiotic factors [38].

Figure 1. Typical headspace gas sampling systems. (a) Static headspace gas sampling with SPME; (b) Dynamic headspace gas sampling connected with absorbents, SPME or PTR-MS.

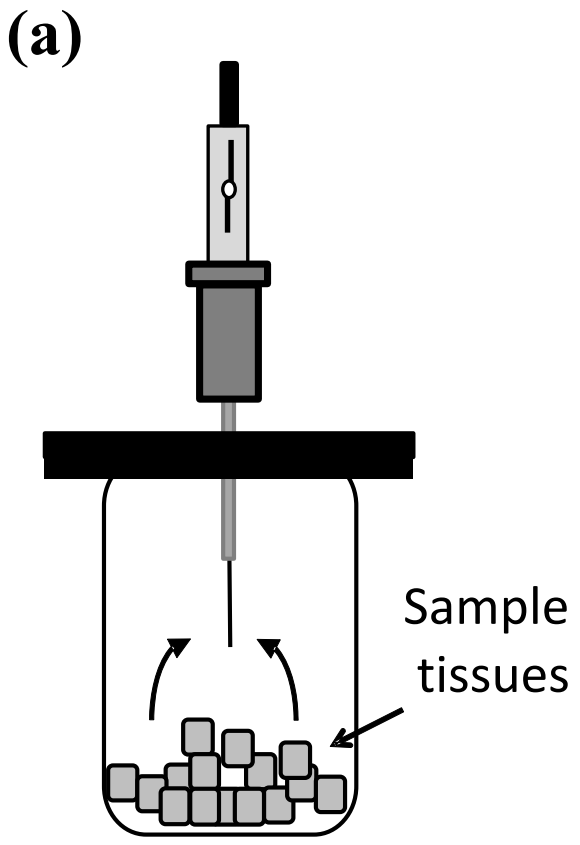
(b) Connected to absorbent,
SPME or PTR-MS

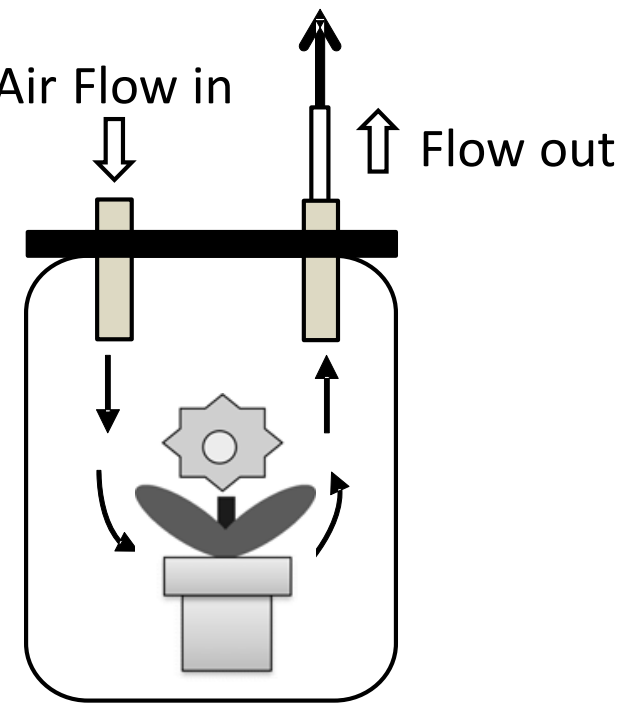

The solvent extraction procedure is sometimes used for VOCs from various samples. In plant materials, solvent extraction is performed to directly extract BVOCs stored in specific tissues, such as trichomes on the surfaces of plants and the flavedo in citrus fruits, and parts of aromatic plants and fruits [36]. Glandular trichomes in Lamiaceae and Solanaceae plants are well known to synthesize volatiles and store them in the subcuticular oil storage cavities on the top of trichomes [46,47]. The membrane of an oil storage cavity is easily disrupted by physical or chemical stimulation; most organic solvents easily penetrate the cellular membrane of the organism and break it. Organic solvent extraction may be, therefore, one of the easiest ways to quickly extract stored volatiles in plant, when a large number of independent samples are required for analysis of BVOCs. For example, mono/sesquiterpene profiles in tomato (Solanum lycopersicum) glandular trichomes were easily obtained from extraction by simply soaking the leaves in methyl t-butyl ether for $1 \mathrm{~min}$ [48]. Homogenized samples are sometimes used for volatile extraction, to improve the extraction efficiency $[49,50]$. 
However, here, we need to recognize that the solvent extracts include de novo synthesized BVOCs and non-/semi-volatile compounds, indicating that the compositional profiles from them are different from those from emitted BVOCs. Furthermore, contamination of non-volatile compounds sometimes disturbs to concentrate BVOC extracts and fouls the injection port of the GC instrument. In addition to the headspace sampling, SPME, and solvent extraction techniques, various steam distillation methods were classically developed and used to collect BVOCs $[1,36]$.

Several technologies for the simple and sensitive detection of VOCs without extraction or adsorption were recently developed. PTR-MS enables the analysis of VOCs in real-time by using proton transfer reagent ions such as $\mathrm{H}_{3} \mathrm{O}^{+}$ions. This is expected to be very effective for analyzing sequential changes in the composition of VOCs. Indeed, differences in the emission patterns of the three green leaf volatiles (Z)-3-hexenal, (Z)-3-hexen-1-ol and (Z)-3-hexen-1-yl acetate after wounding of Arabidopsis leaves were successfully monitored by PTR-MS [51]. Direct analysis in real time ion-source mass spectrometry (DART-MS) can directly ionize the metabolites in gas, liquid and solid samples at atmospheric pressure and detect them by MS [52-54]. Block et al. [55] used DART-MS to directly monitor the sequential metabolic changes of sulfur compounds after crushing garlic (Allium sativum). The properties of PTR-MS and DART-MS in simple, high-throughput, and sequential analyses, are expected in applications for metabolomics.

Imaging mass spectrometry (IMS) using matrix-assisted laser desorption/ionization (MALDI)-MS, atmospheric pressure ion-source chamber for laser desorption/ionization (AP-LDI)-MS, and nano-particle laser desorption/ionization (nano-PALDI)-MS enables the visualization of metabolites in tissues and cells. IMS is very useful to clarify the distribution of the target molecules. Various specialized metabolites stored in the trichomes of wild tomato were recently successfully detected by IMS [56]. As for plant volatiles, the MS ions of monoterpene, diterpene and 6-gingerol were visualized in the tissue of ginger (Zingiber officinale) rhizome by (AP-LDI)-MS microscopy [57]. Compared to the studies of the biosynthesis of plant volatiles, the distribution and transportation of these small molecules in plant tissues, i.e., how these small nonpolar compounds are secreted to the specialized tissues or released to the outside, are not well understood [58]. Therefore, sequential mass images of volatiles in the tissues are expected to help clarify the movement of volatiles among tissues.

\section{Data Mining from Multiple Volatile Profiles by Metabolomics Techniques}

In metabolomics, the techniques used for the data analysis to handle vast data files are very important, as is the sensitive and comprehensive detection of metabolites. Targeted and non-targeted metabolite data analyses and sometimes wide-target metabolite analyses are frequently performed in metabolomics [59,60]. A targeted metabolite analysis focuses on "identified" metabolites whose chemical structures are clear and for which the standard compounds are available. This analysis includes the quantification of each metabolite, contributing to our understanding of the biochemical dynamics and metabolic relationships among the metabolites. In a non-targeted metabolite analysis, all detected peaks including those of unknown compounds are counted comprehensively and then applied to a multivariate analysis such as a principal component analysis (PCA) or partial least squares-discriminant analysis (PLS-DA) analysis. The significant metabolite peaks are then filtered, and their structures are chemically investigated. This is a valuable technique for screening novel 
biomarkers and for finding unexpected metabolites. However, in non-targeted analyses, the frequently detected "unknown" peaks make a detailed analysis difficult, and this has prompted the development of various MS-based peak annotation/identification procedures and metabolite databases [60,61].

In the research for plant volatiles, targeted metabolite analyses are more conventional, because many standard mass spectra for VOCs have accumulated in MS databases and many targeted BVOC profiles of various plant species have been reported. The first volatile analysis termed "metabolomics" was reported for volatile profiling in petunia (Petunia $x$ hybrida) flowers [62]. Regarding non-targeted metabolite analyses for volatiles, a successful new strategy providing an unbiased comparative multivariate analysis was first reported for large-scale data-mining, using 94 genotypes of tomato (S. lycopersicum) fruits [63]. In that analysis, 322 VOCs including unknown compounds were distinguishable, and they were clustered into several groups of biochemically similar compounds in a hierarchical cluster analysis. This innovative analytical strategy provided clues to the biosynthesis and function of unknown metabolites. More recently, non-targeted analyses concerning BVOCs have been used to elucidate the characteristics of wine and carrot (Daucus carota) flavors $[64,65]$, the emission of herbivore-induced VOCs from wild tobacco (Nicotiana attenuata) [66], the biodiversity of pepper (Capsicum sp.) [67], and more. The development of bioinformatics tools focused on plant volatile data has continued to advance [68], and a mass-based automated peak annotation and database system has been developed; it is known as vocBinBase [69].

\section{Application of BVOC Metabolome Analyses to Functional Studies of Volatiles}

\subsection{The Use of BVOC Metabolomics in Chemotaxonomic Studies}

Chemotaxonomy, also called chemosystematics, aims to classify and identify certain organisms according to their metabolic compositions, and to evaluate the organisms' biological diversity and evolution in light of their metabolite diversity. In many cases of plant samples, secondary metabolites are targeted for analysis because their biosynthesis is usually specific to certain plant species [70]. In the typical chemotaxonomic study, varieties of a certain plant species are collected and their metabolic profiles are obtained. After the quantitative data of the targeted metabolite are obtained, a further multivariate analysis, such as a hierarchical clustering analysis (HCA) or PCA, is performed to evaluate similarities among the samples and to identify markers of taxonomic differences.

Thus, the profiling of essential oil, which is constituted of BVOCs was frequently performed in chemotaxonomic studies of medicinal plants and aromatic plants before the concept of metabolomics concept had arisen [71-73]. Terpenes (mono-, and sesqui-) are the most valuable target markers in many plants [74-76]. The relationships between the chemotypic diversity in essential oils and their genetic diversity were investigated in Salvia fruticosa [77], Rosmarinus officinalis [78], and Ocimum gratissimum [79]. This approach in a chemotaxonomic study is very similar to the metabolomics approach. Recent advances in metabolomics and genomics technologies will help accelerate the detailed analyses of the correlations between chemical composition and genetic diversity. 


\subsection{Application of VOC Metabolomics to the Characterization of the Biosynthesis of}

Targeted Volatiles

Metabolomics also has great merit in combination with other "omics" data, such as genomics, transcriptomics, and proteomics. In particular, the correlation of the profiles of gene expressions at the mRNA level and metabolite accumulation will elucidate the gene functions in the biosynthesis of various specialized metabolites [31,60,80,81]. This strategy, called functional genomics, has been used frequently in comparative analyses of plant volatiles, as well as other specialized metabolites. The characterization of gene functions involved in the biosynthesis of specific volatiles has been successfully clarified in various plants (in both model plants and non-model plants) by performing comparative analyses of samples prepared from different varieties/cultivars and different mutant lines, by different physiological conditions such as developmental stages, and in light of the effects of herbivore infestation $[8,82,83]$ (Figure 2).

Figure 2. Metabolomics-driven screening of gene functions for synthesis of BVOCs. This is an example of finding of terpene synthase gene functions involved in aroma of Sweet basil (Ocimum basilicum) [50,84]. Integration of metabolome and transcriptome data facilitated the elucidation of gene function.

Metabolome Analysis (Different Cultivars)

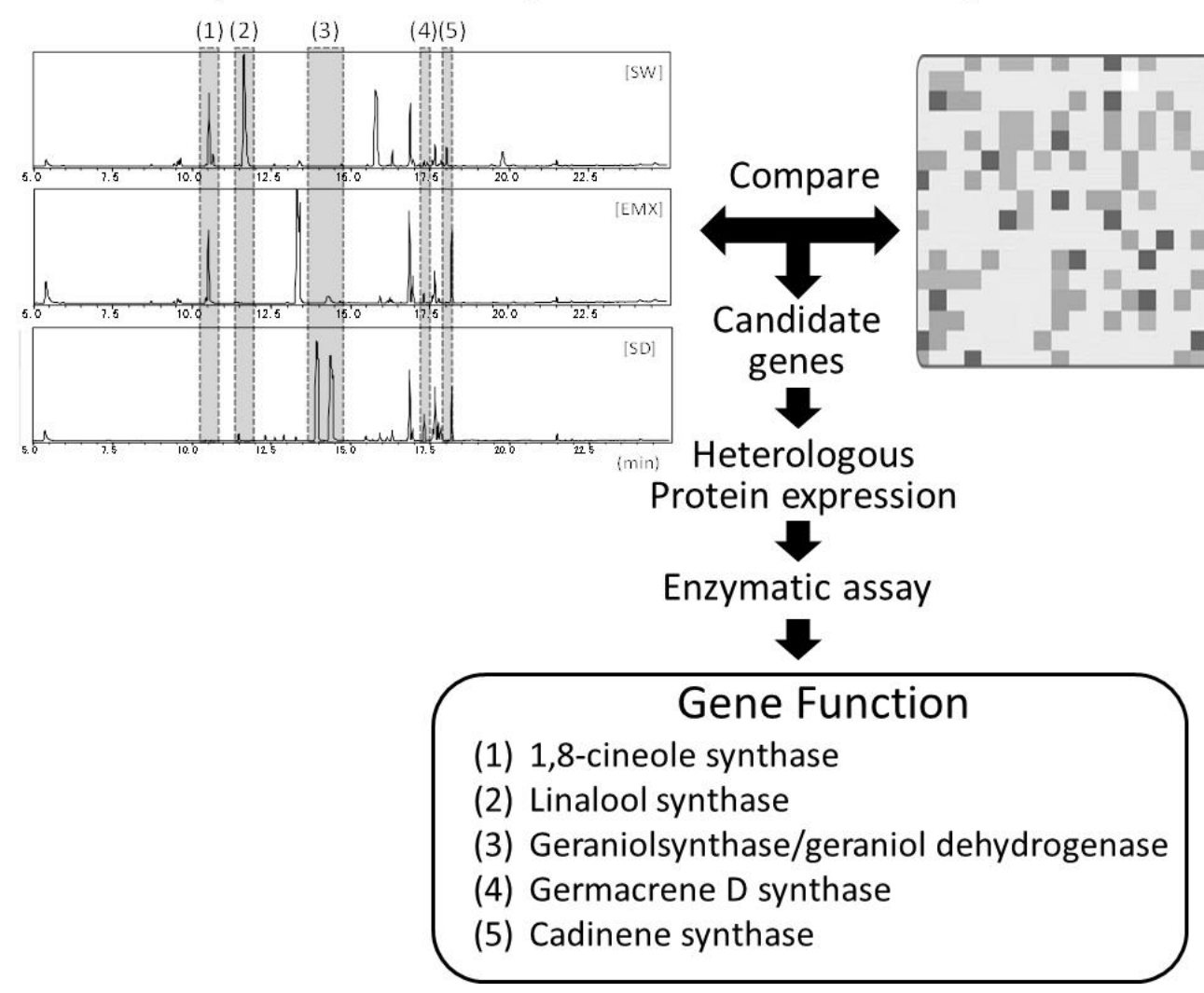

Transcriptome Analysis (Different Cultivars)

西


Here, metabolomics is an indispensable analytical tool for obtaining extensive data from a variety of crossed lines and handling them for QTL analysis [86-89]. The QTL mapping of aroma compounds was conducted for apple (Malus sp., "Discovery" $\times$ "Prima") [90], tomato (S. lycopersicum $\times$ S. pennellii) [91-93], Sorghum bicolor [94], strawberry (Fragaria $\times$ ananassa) [95], and petunia (Petunia axillaris $\times$ Petunia exserta) [96]. Insights provided by metabolite QTL-assisted genome sequencing successfully characterized novel biosynthetic enzymes involved in aroma compounds such as phenylethanol [97], aliphatic alcohol/aldehydes/esters [98], and mono-/sesqui-terpenes [99] from tomato introgression lines (S. lycopersicum $\times$ S. pennellii).

\subsection{Application of Metabolomics to Ecological Studies Concerning Volatiles}

Metabolomics can be used to evaluate a plant's metabolic changes in response to environmental circumstances (i.e., abiotic conditions), e.g., drought conditions, nutrient availability and temperature alteration [100]. Biotic interactions between a plant and other organisms also affect the metabolic dynamics [101,102]. These findings indicate that an ecological condition can induce marked metabolic changes in both the central metabolism and specialized metabolism [14]. Metabolomics has, thus, been received as a powerful analytical methodology in ecological studies [37,100].

BVOCs are also a type of metabolite group influenced by ecological conditions. Many studies indicated that the emission of BVOCs from plant occurs as significant cues, signals, or defense responses to wounding, herbivore infestation, pathogen infection, and pollination [103]. The emitted BVOCs are also known to act as a plant-to-plant communication tool [104]. Interestingly, the composition of emitted BVOCs is frequently influenced by treatment procedures and plant species. In tomato (S. lycopersicum), the BVOC emission was changed by four types of damage treatments: tomato psyllid nymphs (Bactericera cockerelli), cabbage looper caterpillars (Trichoplusia ni Hübner), fall Armyworm caterpillars (Spodoptera frugiperda Smith), and mechanical damage [105]. In cereal crops (wheat, oat, and barley), mechanical injury, beetle (Oulema spp.) herbivory, and fungal infection (Fusarium spp.), induced different ratios of BVOC blends, and, moreover, their composition is different by species [106]. Thus, metabolome data can reveal the differentiation of volatile metabolites by ecological conditions. In many studies, green leaf volatiles and specific terpenoids were found as herbivore-induced compounds by comparative metabolic analyses of damaged and undamaged plants [66,107-109] (Table 1).

The integration of metabolomics with transcriptomics facilitated the elucidation of the biosynthesis of herbivore- and pathogen-induced metabolites, the defense system evoked by damage, and interactions with other organisms [100]. In tomato plants (S. lycopersicum), the influence of a spider mite (Tetranychus urticae) infestation was investigated using a combined metabolome and transcriptome analysis. It was observed that the emission of volatiles, which were preferred by predatory mites occurred several days later than the spider mite-induced defense response, suggesting that volatile production is an indirect defense system that complements the direct defense response against spider mites [110]. In another study, comparative transcriptome and metabolome profiles of pest (Tortrix viridana L.) herbivore-resistant and -susceptible oak (Quercus robur L.) were obtained, and they indicated that the defense system for each cultivar of oak differs at both the transcription and metabolite levels [111]. 
Metabolomics for BVOCs is a reliable technique to investigate physiological events in a plant in response to its circumstances.

\subsection{Application of VOC Metabolomics to Plant Breeding and Quality Evaluations for Commercial Demand}

Metabolomics has contributed to the breeding and biotechnology of crops, with the goal of improving food qualities [112,113], and has been accepted in the fields of horticulture, agriculture and food science [114-116]. In many fruits, vegetables, and herbs, controlling of their aroma and flavor characteristics is one of the significant factors related to improving their qualities [117-120]. Further advances in the quality of food products will require the consideration of not only genotypes/cultivars, but also cultivation conditions and preharvest/postharvest handling.

For these purposes, the most extensively investigated food thus far is tomato (S. lycopersicum) and its products [121]. Over 400 volatiles have been identified in fresh tomato and tomato products $[122,123]$. The differences in sensory characters and BVOC profiles among tomato cultivars and mutants have been examined [63,124-127]. To identify the compounds that affect consumers' tomato preferences, Berna et al. [124] investigated the correlation of aroma profile data with a consumer-preference test using various commercially available tomato cultivars. They concluded that consumer preference is strongly explained by 3-methylbutanol, (E)-2-hexenaol and (Z)-3-hexenol. Cebolla-Cornejo et al. [126] reported that the composition of aroma compounds in a tomato is more affected by genotype than environmental conditions. Tomato is a model plant for climacteric fruits, which produce ethylene and autocatalytically percept it for ripening $[128,129]$. This ripening system regulates various gene expressions controlling fruit softening and the accumulation of various metabolites, such as sugars, acids, amino acids, carotenoids, and aroma compounds [130]. In an investigation of the ripening system in tomato, some mutant lines related to ethylene synthesis or ethylene perception were used for a comparative analysis [131]. Regarding aroma biosynthesis in tomato, a comparative BVOC metabolome analysis within a ripening mutant (rin: ripening inhibitor, nor: non-ripening, Cnr: Colourless nonripening, $N r$ : Never-ripe, $h p 1$ : high pigment mutant 1) indicated that lipid-derived BVOCs such as (Z)-3-hexenal, (E)-2-hexenal, and hexanal are responsible for the differentiation of unripe mutant lines ( $r i n, n o r, C n r$ and $N r$ ) from control and $h p l$ [132]. It was also suggested that the transcription level of TomloxC, a kind of lipoxygenases, is involved in these compositional differences [132].

Other than tomato, insights into screening quality markers provided by metabolomics-driven BVOC profiles were reported for melon (Cucumis melo) [133,134], apple (Malus pumila) [135,136], strawberry (Fragaria $\times$ ananassa) [137], and pepper (Capsicum sp.) [67]. Moreover, recent studies directly emphasized the relationship between some specific aroma compositions and sensory perceptions for consumer preference, for not only food material but also processed food, such as wine [64] and beer [138]. 


\section{Interrelationships between Volatile and Non-Volatile Metabolites Elucidated by Multiplatform Metabolomics Analyses}

The structures of plant-produced BVOCs are categorized mainly into groups of mono-/sesquiterpenoids, benzenoids/phenolics, amino acid derivatives and lipid degradation/derivatives. In many cases, they are terminal products in the entire metabolic pathway in plants, although terpenes are well known to be sometimes modified to semi/non-volatile compounds, for example, by oxygenation in resin ducts of conifer [139]. The amounts of the BVOCs produced are much less than those of other precursor metabolites in the central metabolism. In addition, many VOCs are relatively hydrophobic, whereas most of their precursors and intermediates are highly polar and non-volatile. It is, thus, necessary to view the entirety of the metabolic changes including non-volatile fraction in order to clarify the biosynthesis pathways of BVOCs. Toward this end, metabolome analyses incorporating isotope-labeled precursors are effective for evaluating metabolite flux [140].

Notably, stable isotope-labeled compounds are detected as having $\mathrm{m} / \mathrm{z}$ values that are different from those of endogenous metabolites, indicating that a GC- or LC-MS analysis is useful to follow-up their metabolic flow. In petunia (Petunia hybrida) flower, deuterium-labeled phenylalanine was used to investigate the biosynthetic pathway of benzenoid volatiles, and a combined analysis by GC-MS (for volatiles) and LC-MS (for non-volatiles) successfully identified the pathway of benzenoid synthesis [141].

The emission of BVOCs occurs under various biotic and abiotic conditions. The BVOCs are released through the membranes of the epidermal tissues, stomata, or other specialized structures, such as trichomes and osmophores [37]. Some plants emit airborne BVOCs that are suggested to be taken up into plants at the plant surface via stomatal conductance or cuticle diffusion [104]. In such plant-plant communications, the hormone-like BVOCs methylsalicylate, methyljasmonate, green-leaf volatiles (C6-aldehydes and alcohols) and ethylene, are proposed as communication signals [104].

We were recently the first group to demonstrate that (Z)-3-hexenol, which is a main BVOC emitted from tomato (S. lycopersicum) plants after an infestation with cutworms (Spodoptera litura), was received into a neighboring intact plant (Figure 3). In addition, this received plant showed defense to be infested by this worm. Our non-targeted metabolome analysis of leaves of the receiving plant by GC-MS and LC-MS showed that the incorporated (Z)-3-hexenol was accumulated as a glycoside conjugation (vicianoside) to acquire defense [142]. This finding indicates that incorporated (Z)-3-hexenol is directly metabolized in the leaf tissues. Such accumulations of metabolized BVOCs, mainly glycosylated alcoholic BVOCs, were found in several plants, and they are recognized as important aroma precursors, e.g., in rose (Rosa damascene) petal [143,144], tea (Camellia sinensis) leaf [145], wine grapes (Vitis spp.) [146], and tomato (S. lycopersicum) fruit [147]. Since volatile alcohols are liberated by glycosidase derived from endogenous or microbial enzymes [148], evaluations of the amounts of glycosylated BVOCs could provide a valuable index of flower and food quality. Tikunov et al. [149] performed a non-targeted fusion metabolome analysis with GC-MS for volatiles and LC-MS for non-volatiles in different tomato (S. lycopersicum) genotypes. They found that the emission of phenolic aroma compounds is regulated essentially by the cleavage of their disaccharide derived from cell disruption during tomato ripening, whereas the low phenolic aroma genotypes led to the conjugation of more complicated forms, such as trisaccharides, and malonylated disaccharides. These results indicate the strong potential that multiplatform metabolomics can provide novel findings 
concerning the regulation of BVOC synthesis and the effects of BVOCs on other physiological and ecological functions.

Figure 3. Multiplatform metabolic profiling identified the mechanism of plant-plant communication by green leaf volatiles. (a) Airflow setup for volatile exposure. Intact tomato (S. lycopersicum) plant and the plant damaged by cutworm (S. litura) were prepared; (b) Comparative metabolic profiling of exposed plants by LC-MS analysis. The leaves after exposure of damaged plant volatiles accumulated a specific metabolite; (c) Determination of synthesized metabolite. The structure of it was determined as (Z)-3-hexenyl vicianoside; (d) Weight gains of cutworm (S. litura) on exposed leaves were less than those on control leaves.
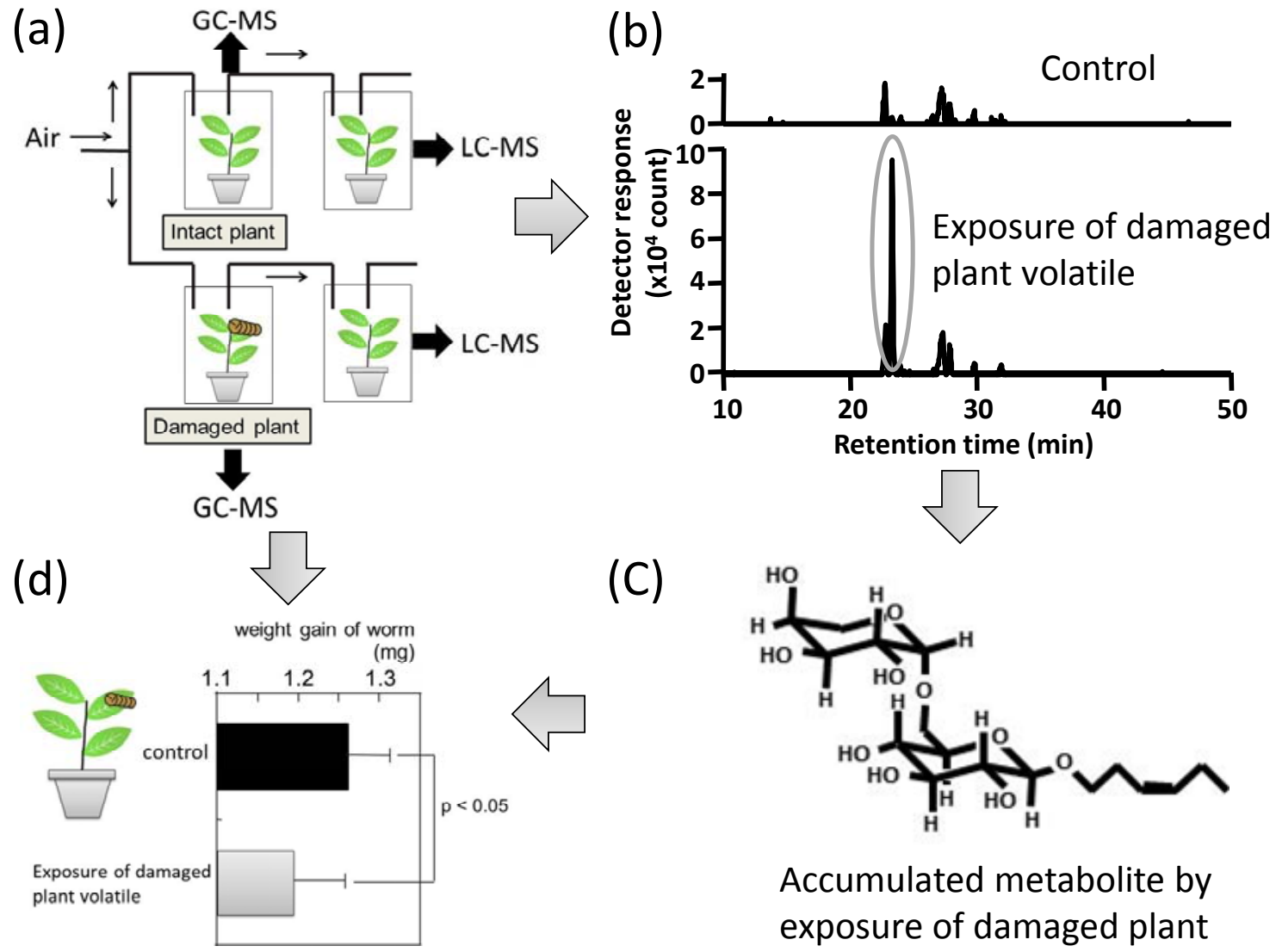

(C)

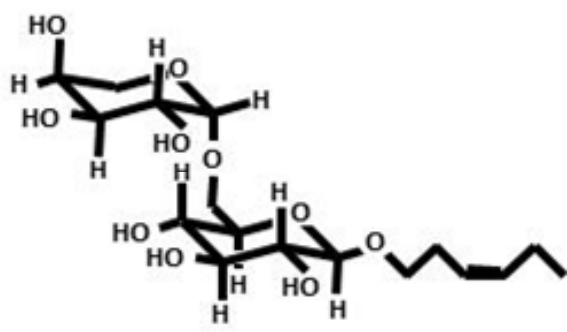

Accumulated metabolite by exposure of damaged plant volatile

\section{Perspective}

Recent BVOC analysis techniques have improved, especially regarding the monitoring of BVOCs' spatial and temporal changes. Although the sensitivity and comprehensiveness of the analyses still need improving, these techniques will contribute to the detailed understanding of the metabolic dynamics of BVOCs. In this review, we focused on metabolomics for the production of BVOCs from plant and their profiles, with only a brief mention of the indirect metabolic changes induced by BVOC reception. Plant defense systems often operate through a jasmonic acid and salicylic acid pathway, affecting the metabolite balance of central metabolites [150]. To systematically identify the effects of VOCs on plants, more extensive metabolome analyses are needed, including those examining central 
metabolites, BVOCs and other non-volatile specialized metabolites. Most BVOCs exist constitutively on the earth. Recent interest in and research into the biological roles of BVOCs have highlighted the potential usefulness of BVOCs in ecosystems. The elucidation of the regulation of BVOC synthesis and the effective mechanisms of each BVOC would also contribute to the metabolic engineering of volatiles [151].

Metabolome data can be applied to cross-analyses with other related quantitative data concerning phyisiological status and olfactometry than metabolites. For instance, in food materials, the determination of the relationship between quantitative sensory evaluation data and metabolome data will be effective for screening the contributing metabolites, and for the prediction of preference models [152]. Thus, improvements in the technologies used for accurate quantitative measurements of physiological and olfactory effects, will help identify the new roles of BVOCs.

\section{Acknowledgments}

I thank Kenji Matsui and Takao Koeduka for critical review of the manuscript. I am also thankful to Koichi Sugimoto and Kenji Matsui for providing figure material (Figure 3).

\section{Conflicts of Interest}

The authors declare no conflict of interest.

\section{References}

1. Rowan, D.D. Volatile metabolites. Metabolites 2011, 1, 41-63.

2. Guenther, A.; Hewitt, C.N.; Erickson, D.; Fall, R.; Geron, C.; Graedel, T.; Harley, P.; Klinger, L.; Lerdau, M.; Mckay, W.A.; et al. A global-model of natural volatile organic-compound emissions. J. Geophys. Res. Atmos. 1995, 100, 8873-8892.

3. Kesselmeier, J.; Staudt, M. Biogenic volatile organic compounds (VOC): An overview on emission, physiology and ecology. J. Atmos. Chem. 1999, 33, 23-88.

4. Penuelas, J.; Staudt, M. BVOCs and global change. Trends Plant Sci. 2010, 15, 133-144.

5. Knudsen, J.T.; Gershenzon, J. The chemical diversity of floral scent. In Biology of Floral Scent; Dudareva, N., Pichersky, E., Eds.; CRC Press Taylor \&Francis Group: Boca Raton, FL, USA, 2006; pp. 27-52.

6. Courtois, E.A.; Paine, C.E.T.; Blandinieres, P.A.; Stien, D.; Bessiere, J.M.; Houel, E.; Baraloto, C.; Chave, J. Diversity of the volatile organic compounds emitted by 55 species of tropical trees: A survey in French guiana. J. Chem. Ecol. 2009, 35, 1349-1362.

7. Dudareva, N.; Klempien, A.; Muhlemann, J.K.; Kaplan, I. Biosynthesis, function and metabolic engineering of plant volatile organic compounds. New Phytol. 2013, 198, 16-32.

8. Pichersky, E.; Noel, J.P.; Dudareva, N. Biosynthesis of plant volatiles: Nature's diversity and ingenuity. Science 2006, 311, 808-811.

9. Allison, J.D.; Daniel Hare, J. Learned and naive natural enemy responses and the interpretation of volatile organic compounds as cues or signals. New Phytol. 2009, 184, 768-782. 
10. Arimura, G.; Shiojiri, K.; Karban, R. Acquired immunity to herbivory and allelopathy caused by airborne plant emissions. Phytochemistry 2010, 71, 1642-1649.

11. Farag, M.A.; Zhang, H.M.; Ryu, C.M. Dynamic chemical communication between plants and bacteria through airborne signals: Induced resistance by bacterial volatiles. J. Chem. Ecol. 2013, 39, 1007-1018.

12. Holopainen, J.K.; Blande, J.D. Where do herbivore-induced plant volatiles go? Front. Plant Sci. 2013, 4, 185.

13. Kessler, A.; Baldwin, I.T. Defensive function of herbivore-induced plant volatile emissions in nature. Science 2001, 291, 2141-2144.

14. Mithofer, A.; Boland, W. Plant defense against herbivores: Chemical aspects. Annu. Rev. Plant Biol. 2012, 63, 431-450.

15. Schwab, W.; Davidovich-Rikanati, R.; Lewinsohn, E. Biosynthesis of plant-derived flavor compounds. Plant J. 2008, 54, 712-732.

16. Sangwan, N.S.; Farooqi, A.H.A.; Shabih, F.; Sangwan, R.S. Regulation of essential oil production in plants. Plant Growth Regul. 2001, 34, 3-21.

17. Bakkali, F.; Averbeck, S.; Averbeck, D.; Idaomar, M. Biological effects of essential oils-A review. Food Chem. Toxicol. 2008, 46, 446-475.

18. Baratta, M.T.; Dorman, H.J.D.; Deans, S.G.; Figueiredo, A.C.; Barroso, J.G.; Ruberto, G. Antimicrobial and antioxidant properties of some commercial essential oils. Flavour Fragr. J. 1998, 13, 235-244.

19. Burt, S. Essential oils: Their antibacterial properties and potential applications in foods-A review. Int. J. Food Microbiol. 2004, 94, 223-253.

20. Ruberto, G.; Baratta, M.T. Antioxidant activity of selected essential oil components in two lipid model systems. Food Chem. 2000, 69, 167-174.

21. Sacchetti, G.; Maietti, S.; Muzzoli, M.; Scaglianti, M.; Manfredini, S.; Radice, M.; Bruni, R. Comparative evaluation of 11 essential oils of different origin as functional antioxidants, antiradicals and antimicrobials in foods. Food Chem. 2005, 91, 621-632.

22. Qualley, A.V.; Dudareva, N. Metabolomics of plant volatiles. Methods Mol. Biol. 2009, 553, 329-343.

23. Alves, R.F.; Nascimento, A.M.D.; Nogueira, J.M.F. Characterization of the aroma profile of madeira wine by sorptive extraction techniques. Anal. Chim. Acta 2005, 546, 11-21.

24. Bicchi, C.; Liberto, E.; Matteodo, M.; Sgorbini, B.; Mondello, L.; Zellner, B.A.; Costa, R.; Rubiolo, P. Quantitative analysis of essential oils: A complex task. Flavour Fragr. J. 2008, 23, 382-391.

25. Chun, M.-H.; Kim, E.K.; Yu, S.M.; Oh, M.S.; Moon, K.-Y.; Jung, J.H.; Hong, J. GC/MS combined with chemometrics methods for quality control of Schizonepeta tenuifolia Briq: Determination of essential oils. Microchem. J. 2011, 97, 274-281.

26. Gutierrez, J.; Bourke, P.; Lonchamp, J.; Barry-Ryan, C. Impact of plant essential oils on microbiological, organoleptic and quality markers of minimally processed vegetables. Innov. Food Sci. Emerg. Technol. 2009, 10, 195-202. 
27. Tzouros, N.E.; Arvanitoyannis, I.S. Agricultural produces: Synopsis of employed quality control methods for the authentication of foods and application of chemometrics for the classification of foods according to their variety or geographical origin. Crit. Rev. Food Sci. 2001, 41, 287-319.

28. Vichi, S.; Pizzale, L.; Conte, L.S.; Buxaderas, S.; López-Tamames, E. Solid-phase microextraction in the analysis of virgin olive oil volatile fraction: Characterization of virgin olive oils from two distinct geographical areas of northern Italy. J. Agric. Food Chem. 2003, 51, 6572-6577.

29. Fiehn, O. Metabolomics - The link between genotypes and phenotypes. Plant Mol. Biol. 2002, $48,155-171$.

30. Sumner, L.W.; Mendes, P.; Dixon, R.A. Plant metabolomics: Large-scale phytochemistry in the functional genomics era. Phytochemistry 2003, 62, 817-836.

31. Bino, R.J.; Hall, R.D.; Fiehn, O.; Kopka, J.; Saito, K.; Draper, J.; Nikolau, B.J.; Mendes, P.; Roessner-Tunali, U.; Beale, M.H.; et al. Potential of metabolomics as a functional genomics tool. Trends Plant Sci. 2004, 9, 418-425.

32. Goodacre, R.; Vaidyanathan, S.; Dunn, W.B.; Harrigan, G.G.; Kell, D.B. Metabolomics by numbers: Acquiring and understanding global metabolite data. Trends Biotechnol. 2004, 22, 245-252.

33. Beck, J.J.; Smith, L.; Baig, N. An overview of plant volatile metabolomics, sample treatment and reporting considerations with emphasis on mechanical damage and biological control of weeds. Phytochem. Anal. 2013, 25, 331-341.

34. Bicchi, C.; Maffei, M. The plant volatilome: Methods of analysis. Methods Mol. Biol. 2012, 918 , 289-310.

35. Maffei, M.E.; Gertsch, J.; Appendino, G. Plant volatiles: Production, function and pharmacology. Nat. Prod. Rep. 2011, 28, 1359-1380.

36. Ormeño, E.; Goldstein, A.; Niinemets, Ü. Extracting and trapping biogenic volatile organic compounds stored in plant species. Trends Anal. Chem. 2011, 30, 978-989.

37. Baldwin, I.T. Plant volatiles. Curr. Biol. 2010, 20, R392-R397.

38. Tholl, D.; Boland, W.; Hansel, A.; Loreto, F.; Rose, U.S.; Schnitzler, J.P. Practical approaches to plant volatile analysis. Plant $J$. 2006, 45, 540-560.

39. Kusano, M.; Iizuka, Y.; Kobayashi, M.; Fukushima, A.; Saito, K. Development of a direct headspace collection method from arabidopsis seedlings using HS-SPME-GC-TOF-MS analysis. Metabolites 2013, 3, 223-242.

40. Risticevic, S.; Pawliszyn, J. Solid-phase microextraction in targeted and nontargeted analysis: Displacement and desorption effects. Anal. Chem. 2013, 85, 8987-8995.

41. David, F.; Sandra, P. Stir bar sorptive extraction for trace analysis. J. Chromatogr. A 2007, 1152, 54-69.

42. Gamero, A.; Wesselink, W.; de Jong, C. Comparison of the sensitivity of different aroma extraction techniques in combination with gas chromatography-mass spectrometry to detect minor aroma compounds in wine. J. Chromatogr. A 2013, 1272, 1-7.

43. Salinas, M.; Zalacain, A.; Pardo, F.; Alonso, G.L. Stir bar sorptive extraction applied to volatile constituents evolution during Vitis vinifera ripening. J. Agric. Food Chem. 2004, 52, 4821-4827. 
44. Kännaste, A.; Copolovici, L.; Niinemets, Ü. Gas chromatography-mass spectrometry method for determination of biogenic volatile organic compounds emitted by plants. In Plant Isoprenoids; Rodríguez-Concepción, M., Ed.; Springer: New York, NY, USA, 2014; Volume 1153, pp. 161-169.

45. Niinemets, Ü.; Kuhn, U.; Harley, P.C.; Staudt, M.; Arneth, A.; Cescatti, A.; Ciccioli, P.; Copolovici, L.; Geron, C.; Guenther, A.; et al. Estimations of isoprenoid emission capacity from enclosure studies: Measurements, data processing, quality and standardized measurement protocols. Biogeosciences 2011, 8, 2209-2246.

46. Lange, B.M.; Turner, G.W. Terpenoid biosynthesis in trichomes-current status and future opportunities. Plant Biotechnol. J. 2013, 11, 2-22.

47. Turner, G.W.; Gershenzon, J.; Croteau, R.B. Distribution of peltate glandular trichomes on developing leaves of peppermint. Plant Physiol. 2000, 124, 655-664.

48. Schilmiller, A.L.; Schauvinhold, I.; Larson, M.; Xu, R.; Charbonneau, A.L.; Schmidt, A.; Wilkerson, C.; Last, R.L.; Pichersky, E. Monoterpenes in the glandular trichomes of tomato are synthesized from a neryl diphosphate precursor rather than geranyl diphosphate. Proc. Natl. Acad. Sci. USA 2009, 106, 10865-10870.

49. Gang, D.R.; Wang, J.; Dudareva, N.; Nam, K.H.; Simon, J.E.; Lewinsohn, E.; Pichersky, E. An investigation of the storage and biosynthesis of phenylpropenes in sweet basil. Plant Physiol. 2001, 125, 539-555.

50. Iijima, Y.; Davidovich-Rikanati, R.; Fridman, E.; Gang, D.R.; Bar, E.; Lewinsohn, E.; Pichersky, E. The biochemical and molecular basis for the divergent patterns in the biosynthesis of terpenes and phenylpropenes in the peltate glands of three cultivars of basil. Plant Physiol. 2004, 136, 3724-3736.

51. D'Auria, J.C.; Pichersky, E.; Schaub, A.; Hansel, A.; Gershenzon, J. Characterization of a BAHD acyltransferase responsible for producing the green leaf volatile (Z)-3-hexen-1-yl acetate in Arabidopsis thaliana. Plant J. 2007, 49, 194-207.

52. Cody, R.B. Observation of molecular ions and analysis of nonpolar compounds with the direct analysis in real time ion source. Anal. Chem. 2008, 81, 1101-1107.

53. Hajslova, J.; Cajka, T.; Vaclavik, L. Challenging applications offered by direct analysis in real time (DART) in food-quality and safety analysis. Trends Anal. Chem. 2011, 30, 204-218.

54. Yu, S.; Crawford, E.; Tice, J.; Musselman, B.; Wu, J.-T. Bioanalysis without sample cleanup or chromatography: The evaluation and initial implementation of direct analysis in real time ionization mass spectrometry for the quantification of drugs in biological matrixes. Anal. Chem. 2008, 81, 193-202.

55. Block, E.; Dane, A.J.; Thomas, S.; Cody, R.B. Applications of direct analysis in real time mass spectrometry (DART-MS) in allium chemistry. 2-propenesulfenic and 2-propenesulfinic acids, diallyl trisulfane s-oxide, and other reactive sulfur compounds from crushed garlic and other alliums. J. Agric. Food Chem. 2010, 58, 4617-4625.

56. Li, C.; Wang, Z.Z.; Jones, A.D. Chemical imaging of trichome specialized metabolites using contact printing and laser desorption/ionization mass spectrometry. Anal. Bioanal. Chem. 2014, 406, 171-182. 
57. Harada, T.; Yuba-Kubo, A.; Sugiura, Y.; Zaima, N.; Hayasaka, T.; Goto-Inoue, N.; Wakui, M.; Suematsu, M.; Takeshita, K.; Ogawa, K.; et al. Visualization of volatile substances in different organelles with an atmospheric-pressure mass microscope. Anal. Chem. 2009, 81, 9153-9157.

58. Linka, N.; Theodoulou, F.L. Metabolite transporters of the plant peroxisomal membrane: Known and unknown. Sub Cell Biochem. 2013, 69, 169-194.

59. Kueger, S.; Steinhauser, D.; Willmitzer, L.; Giavalisco, P. High-resolution plant metabolomics: From mass spectral features to metabolites and from whole-cell analysis to subcellular metabolite distributions. Plant J. 2012, 70, 39-50.

60. Saito, K.; Matsuda, F. Metabolomics for functional genomics, systems biology, and biotechnology. Annu. Rev. Plant Biol. 2010, 61, 463-489.

61. Ogura, T.; Bamba, T.; Fukusaki, E. Development of a practical metabolite identification technique for non-targeted metabolomics. J. Chromatogr. A 2013, 1301, 73-79.

62. Verdonk, J.C.; de Vos, C.H.R.; Verhoeven, H.A.; Haring, M.A.; van Tunen, A.J.; Schuurink, R.C. Regulation of floral scent production in petunia revealed by targeted metabolomics. Phytochemistry 2003, 62, 997-1008.

63. Tikunov, Y.; Lommen, A.; de Vos, C.H.R.; Verhoeven, H.A.; Bino, R.J.; Hall, R.D.; Bovy, A.G. A novel approach for nontargeted data analysis for metabolomics. Large-scale profiling of tomato fruit volatiles. Plant Physiol. 2005, 139, 1125-1137.

64. Schmidtke, L.M.; Blackman, J.W.; Clark, A.C.; Grant-Preece, P. Wine metabolomics: Objective measures of sensory properties of semillon from GC-MS profiles. J. Agric. Food Chem. 2013, $61,11957-11967$.

65. Kebede, B.T.; Grauwet, T.; Palmers, S.; Vervoort, L.; Carle, R.; Hendrickx, M.; Van Loey, A. Effect of high pressure high temperature processing on the volatile fraction of differently coloured carrots. Food Chem. 2014, 153, 340-352.

66. Gaquerel, E.; Weinhold, A.; Baldwin, I.T. Molecular interactions between the specialist herbivore Manduca sexta (Lepidoptera, Sphigidae) and its natural host Nicotiana attenuata. VIII. An unbiased GCxGC-TOFMS analysis of the plant's elicited volatile emissions. Plant Physiol. 2009, 149, 1408-1423.

67. Wahyuni, Y.; Ballester, A.R.; Tikunov, Y.; de Vos, R.C.H.; Pelgrom, K.T.B.; Maharijaya, A.; Sudarmonowati, E.; Bino, R.J.; Bovy, A.G. Metabolomics and molecular marker analysis to explore pepper (Capsicum sp.) biodiversity. Metabolomics 2013, 9, 130-144.

68. Van Dam, N.M.; Poppy, G.M. Why plant volatile analysis needs bioinformatics-Detecting signal from noise in increasingly complex profiles. Plant Biol. 2008, 10, $29-37$.

69. Skogerson, K.; Wohlgemuth, G.; Barupal, D.K.; Fiehn, O. The volatile compound binbase mass spectral database. BMC Bioinform. 2011, 12, 321.

70. Hegnauer, R. Phytochemistry and plant taxonomy-An essay on the chemotaxonomy of higher plants. Phytochemistry 1986, 25, 1519-1535.

71. Barra, A. Factors affecting chemical variability of essential oils: A review of recent developments. Nat. Prod. Commun. 2009, 4, 1147-1154.

72. Grayer, R.J.; Kite, G.C.; Goldstone, F.J.; Bryan, S.E.; Paton, A.; Putievsky, E. Infraspecific taxonomy and essential oil chemotypes in sweet basil, Ocimum basilicum. Phytochemistry 1996, 43, 1033-1039. 
73. Smelcerovic, A.; Spiteller, M.; Ligon, A.P.; Smelcerovic, Z.; Raabe, N. Essential oil composition of Hypericum L. Species from southeastern Serbia and their chemotaxonomy. Biochem. Syst. Ecol. 2007, 35, 99-113.

74. Hillig, K.W. A chemotaxonomic analysis of terpenoid variation in Cannabis. Biochem. Syst. Ecol. 2004, 32, 875-891.

75. Schulz, H.; Baranska, M.; Belz, H.-H.; Rösch, P.; Strehle, M.A.; Popp, J. Chemotaxonomic characterisation of essential oil plants by vibrational spectroscopy measurements. Vib. Spectrosc. 2004, 35, 81-86.

76. Zavarin, E.; Snajberk, K. Chemotaxonomy of the Genus abies-I.: Survey of the terpenes present in the abies balsams. Phytochemistry 1965, 4, 141-148.

77. Skoula, M.; Hilali, I.E.; Makris, A.M. Evaluation of the genetic diversity of Salvia fruticosa Mill. Clones using rapd markers and comparison with the essential oil profiles. Biochem. Syst. Ecol. 1999, 27, 559-568.

78. Angioni, A.; Barra, A.; Cereti, E.; Barile, D.; Coïsson, J.D.; Arlorio, M.; Dessi, S.; Coroneo, V.; Cabras, P. Chemical composition, plant genetic differences, antimicrobial and antifungal activity investigation of the essential oil of Rosmarinus officinalis L. J. Agric. Food Chem. 2004, 52, 3530-3535.

79. Vieira, R.F.; Grayer, R.J.; Paton, A.; Simon, J.E. Genetic diversity of Ocimum gratissimum L. Based on volatile oil constituents, flavonoids and RAPD markers. Biochem. Syst. Ecol. 2001, 29, 287-304.

80. Tohge, T.; Nishiyama, Y.; Hirai, M.Y.; Yano, M.; Nakajima, J.; Awazuhara, M.; Inoue, E.; Takahashi, H.; Goodenowe, D.B.; Kitayama, M.; et al. Functional genomics by integrated analysis of metabolome and transcriptome of Arabidopsis plants over-expressing an MYB transcription factor. Plant J. 2005, 42, 218-235.

81. Yonekura-Sakakibara, K.; Saito, K. Functional genomics for plant natural product biosynthesis. Nat. Prod. Rep. 2009, 26, 1466-1487.

82. Dudareva, N.; Pichersky, E.; Gershenzon, J. Biochemistry of plant volatiles. Plant Physiol. 2004, 135, 1893-1902.

83. Tholl, D. Terpene synthases and the regulation, diversity and biological roles of terpene metabolism. Curr. Opin. Plant Biol. 2006, 9, 297-304.

84. Xie, Z.; Kapteyn, J.; Gang, D.R. A systems biology investigation of the MEP/terpenoid and shikimate/phenylpropanoid pathways points to multiple levels of metabolic control in sweet basil glandular trichomes. Plant J. 2008, 54, 349-361.

85. Fernie, A.R.; Klee, H.J. The use of natural genetic diversity in the understanding of metabolic organization and regulation. Front. Plant Sci. 2011, 2, 59.

86. Matsuda, F.; Okazaki, Y.; Oikawa, A.; Kusano, M.; Nakabayashi, R.; Kikuchi, J.; Yonemaru, J.I.; Ebana, K.; Yano, M.; Saito, K. Dissection of genotype-phenotype associations in rice grains using metabolome quantitative trait loci analysis. Plant J. 2012, 70, 624-636.

87. Nicholson, G.; Rantalainen, M.; Li, J.V.; Maher, A.D.; Malmodin, D.; Ahmadi, K.R.; Faber, J.H.; Barrett, A.; Min, J.L.; Rayner, N.W.; et al. A genome-wide metabolic QTL analysis in Europeans implicates two loci shaped by recent positive selection. PLoS Genet. 2011, 7, e1002270. 
88. Perez-Fons, L.; Wells, T.; Corol, D.I.; Ward, J.L.; Gerrish, C.; Beale, M.H.; Seymour, G.B.; Bramley, P.M.; Fraser, P.D. A genome-wide metabolomic resource for tomato fruit from Solanum pennellii. Sci. Rep. UK 2014, 4, 3859.

89. Schauer, N.; Semel, Y.; Balbo, I.; Steinfath, M.; Repsilber, D.; Selbig, J.; Pleban, T.; Zamir, D.; Fernie, A.R. Mode of inheritance of primary metabolic traits in tomato. Plant Cell 2008, 20, 509-523.

90. Dunemann, F.; Ulrich, D.; Boudichevskaia, A.; Grafe, C.; Weber, W.E. QTL mapping of aroma compounds analysed by headspace solid-phase microextraction gas chromatography in the apple progeny "Discovery" × "Prima". Mol. Breed. 2009, 23, 501-521.

91. Mathieu, S.; Cin, V.D.; Fei, Z.; Li, H.; Bliss, P.; Taylor, M.G.; Klee, H.J.; Tieman, D.M. Flavour compounds in tomato fruits: Identification of loci and potential pathways affecting volatile composition. J. Exp. Bot. 2009, 60, 325-337.

92. Tieman, D.M.; Zeigler, M.; Schmelz, E.A.; Taylor, M.G.; Bliss, P.; Kirst, M.; Klee, H.J. Identification of loci affecting flavour volatile emissions in tomato fruits. J. Exp. Bot. 2006, 57, 887-896.

93. Zanor, M.I.; Rambla, J.L.; Chaib, J.; Steppa, A.; Medina, A.; Granell, A.; Fernie, A.R.; Causse, M. Metabolic characterization of loci affecting sensory attributes in tomato allows an assessment of the influence of the levels of primary metabolites and volatile organic contents. J. Exp. Bot. 2009, 60, 2139-2154.

94. Yundaeng, C.; Somta, P.; Tangphatsornruang, S.; Wongpornchai, S.; Srinives, P. Gene discovery and functional marker development for fragrance in sorghum (Sorghum bicolor (L.) moench). Theor. Appl. Genet. 2013, 126, 2897-2906.

95. Zorrilla-Fontanesi, Y.; Rambla, J.L.; Cabeza, A.; Medina, J.J.; Sanchez-Sevilla, J.F.; Valpuesta, V.; Botella, M.A.; Granell, A.; Amaya, I. Genetic analysis of strawberry fruit aroma and identification of $O$-methyltransferase $F a O M T$ as the locus controlling natural variation in mesifurane content. Plant Physiol. 2012, 159, 851-870.

96. Klahre, U.; Gurba, A.; Hermann, K.; Saxenhofer, M.; Bossolini, E.; Guerin, P.M.; Kuhlemeier, C. Pollinator choice in petunia depends on two major genetic loci for floral scent production. Curr. Biol. 2011, 21, 730-739.

97. Tieman, D.; Taylor, M.; Schauer, N.; Fernie, A.R.; Hanson, A.D.; Klee, H.J. Tomato aromatic amino acid decarboxylases participate in synthesis of the flavor volatiles 2-phenylethanol and 2-phenylacetaldehyde. Proc. Natl. Acad. Sci. USA 2006, 103, 8287-8292.

98. Goulet, C.; Mageroy, M.H.; Lam, N.B.; Floystad, A.; Tieman, D.M.; Klee, H.J. Role of an esterase in flavor volatile variation within the tomato clade. Proc. Natl. Acad. Sci. USA 2012, 109, 19009-19014.

99. Matsuba, Y.; Nguyen, T.T.H.; Wiegert, K.; Falara, V.; Gonzales-Vigil, E.; Leong, B.; Schafer, P.; Kudrna, D.; Wing, R.A.; Bolger, A.M.; et al. Evolution of a complex locus for terpene biosynthesis in Solanum. Plant Cell 2013, 25, 2022-2036.

100. Sardans, J.; Penuelas, J.; Rivas-Ubach, A. Ecological metabolomics: Overview of current developments and future challenges. Chemoecology 2011, 21, 191-225.

101. Dicke, M.; van Loon, J.J.A.; Soler, R. Chemical complexity of volatiles from plants induced by multiple attack. Nat. Chem. Biol. 2009, 5, 317-324. 
102. Jansen, J.J.; Allwood, J.W.; Marsden-Edwards, E.; van der Putten, W.H.; Goodacre, R.; van Dam, N.M. Metabolomic analysis of the interaction between plants and herbivores. Metabolomics 2009, 5, 150-161.

103. Schiestl, F.P.; Johnson, S.D. Pollinator-mediated evolution of floral signals. Trends Ecol. Evol. 2013, 28, 307-315.

104. Baldwin, I.T.; Halitschke, R.; Paschold, A.; von Dahl, C.C.; Preston, C.A. Volatile signaling in plant-plant interactions: "Talking trees" in the genomics era. Science 2006, 311, 812-815.

105. Bautista-Lozada, A.; Espinosa-Garcia, F.J. Odor uniformity among tomato individuals in response to herbivore depends on insect species. PLoS One 2013, 8, e77199.

106. Piesik, D.; Pańka, D.; Delaney, K.J.; Skoczek, A.; Lamparski, R.; Weaver, D.K. Cereal crop volatile organic compound induction after mechanical injury, beetle herbivory (Oulema spp.), or fungal infection (Fusarium spp.). J. Plant Physiol. 2011, 168, 878-886.

107. Arimura, G.; Matsui, K.; Takabayashi, J. Chemical and molecular ecology of herbivore-induced plant volatiles: Proximate factors and their ultimate functions. Plant Cell Physiol. 2009, 50, 911-923.

108. Degen, T.; Dillmann, C.; Marion-Poll, F.; Turlings, T.C. High genetic variability of herbivore-induced volatile emission within a broad range of maize inbred lines. Plant Physiol. 2004, 135, 1928-1938.

109. Scala, A.; Allmann, S.; Mirabella, R.; Haring, M.A.; Schuurink, R.C. Green leaf volatiles: A plant's multifunctional weapon against herbivores and pathogens. Int. J. Mol. Sci. 2013, 14, 17781-17811.

110. Kant, M.R.; Ament, K.; Sabelis, M.W.; Haring, M.A.; Schuurink, R.C. Differential timing of spider mite-induced direct and indirect defenses in tomato plants. Plant Physiol. 2004, 135, 483-495.

111. Kersten, B.; Ghirardo, A.; Schnitzler, J.P.; Kanawati, B.; Schmitt-Kopplin, P.; Fladung, M.; Schroeder, H. Integrated transcriptomics and metabolomics decipher differences in the resistance of pedunculate oak to the herbivore Tortrix viridana L. BMC Genomics 2013, 14, 737.

112. Davies, H.V.; Shepherd, L.V.T.; Stewart, D.; Frank, T.; Röhlig, R.M.; Engel, K.-H. Metabolome variability in crop plant species-When, where, how much and so what? Regul. Toxicol. Pharmacol. 2010, 58, S54-S61.

113. Fernie, A.R.; Schauer, N. Metabolomics-assisted breeding: A viable option for crop improvement? Trends Genet. 2009, 25, 39-48.

114. Cevallos-Cevallos, J.M.; Reyes-De-Corcuera, J.I.; Etxeberria, E.; Danyluk, M.D.; Rodrick, G.E. Metabolomic analysis in food science: A review. Trends Food Sci. Technol. 2009, 20, 557-566.

115. Herrero, M.; Simó, C.; García-Cañas, V.; Ibáñez, E.; Cifuentes, A. Foodomics: MS-based strategies in modern food science and nutrition. Mass Spectrom. Rev. 2012, 31, 49-69.

116. Wishart, D.S. Metabolomics: Applications to food science and nutrition research. Trends Food Sci. Technol. 2008, 19, 482-493.

117. Baldwin, E.A. Fruit flavor, volatile metabolism and consumer perceptions. In Fruit Quality and Its Biological Basis; Knee, M., Ed.; CRC Press: Boca Raton, FL, USA; pp. 89-106.

118. Goff, S.A.; Klee, H.J. Plant volatile compounds: Sensory cues for health and nutritional value? Science 2006, 311, 815-819. 
119. Hall, R.D.; Brouwer, I.D.; Fitzgerald, M.A. Plant metabolomics and its potential application for human nutrition. Physiol. Plant. 2008, 132, 162-175.

120. Klee, H.J. Improving the flavor of fresh fruits: Genomics, biochemistry, and biotechnology. New Phytol. 2010, 187, 44-56.

121. Davies, J.N.; Hobson, G.E.; McGlasson, W.B. The constituents of tomato fruit-The influence of environment, nutrition, and genotype. Crit. Rev. Food Sci. Nutr. 1981, 15, 205-280.

122. Kazeniac, S.J.; Hall, R.M. Flavor chemistry of tomato volatiles. J. Food Sci. 1970, 35, 519-530.

123. Petro-Turza, M. Flavor of tomato and tomato products. Food Rev. Int. 1986, 2, 309-351.

124. Berna, A.Z.; Lammertyn, J.; Buysens, S.; Di Natale, C.; Nicolaï, B.M. Mapping consumer liking of tomatoes with fast aroma profiling techniques. Postharvest Biol. Technol. 2005, 38, 115-127.

125. Bino, R.J.; De Vos, C.H.R.; Lieberman, M.; Hall, R.D.; Bovy, A.; Jonker, H.H.; Tikunov, Y.; Lommen, A.; Moco, S.; Levin, I. The light-hyperresponsive high pigment-2dg mutation of tomato: Alterations in the fruit metabolome. New Phytol. 2005, 166, 427-438.

126. Cebolla-Cornejo, J.; Roselló, S.; Valcárcel, M.; Serrano, E.; Beltrán, J.; Nuez, F. Evaluation of genotype and environment effects on taste and aroma flavor components of spanish fresh tomato varieties. J. Agric. Food Chem. 2011, 59, 2440-2450.

127. Langlois, D.; Etievant, P.X.; Pierron, P.; Jorrot, A. Sensory and instrumental characterisation of commercial tomato varieties. Z. Lebensm. Unters. Forsch. 1996, 203, 534-540.

128. Alexander, L.; Grierson, D. Ethylene biosynthesis and action in tomato: A model for climacteric fruit ripening. J. Exp. Bot. 2002, 53, 2039-2055.

129. Gapper, N.; McQuinn, R.; Giovannoni, J. Molecular and genetic regulation of fruit ripening. Plant Mol. Biol. 2013, 82, 575-591.

130. Klee, H.J.; Giovannoni, J.J. Genetics and control of tomato fruit ripening and quality attributes. Annu. Rev. Genet. 2011, 45, 41-59.

131. Osorio, S.; Alba, R.; Damasceno, C.M.; Lopez-Casado, G.; Lohse, M.; Zanor, M.I.; Tohge, T.; Usadel, B.; Rose, J.K.; Fei, Z.; et al. Systems biology of tomato fruit development: Combined transcript, protein, and metabolite analysis of tomato transcription factor (nor, rin) and ethylene receptor $(\mathrm{Nr})$ mutants reveals novel regulatory interactions. Plant Physiol. 2011, 157, 405-425.

132. Kovács, K.; Fray, R.G.; Tikunov, Y.; Graham, N.; Bradley, G.; Seymour, G.B.; Bovy, A.G.; Grierson, D. Effect of tomato pleiotropic ripening mutations on flavour volatile biosynthesis. Phytochemistry 2009, 70, 1003-1008.

133. Allwood, J.W.; Cheung, W.; Xu, Y.; Mumm, R.; De Vos, R.C.H.; Deborde, C.; Biais, B.; Maucourt, M.; Berger, Y.; Schaffer, A.A.; et al. Metabolomics in melon: A new opportunity for aroma analysis. Phytochemistry 2014, 99, 61-72.

134. Moing, A.; Aharoni, A.; Biais, B.; Rogachev, I.; Meir, S.; Brodsky, L.; Allwood, J.W.; Erban, A.; Dunn, W.B.; Kay, L.; et al. Extensive metabolic cross-talk in melon fruit revealed by spatial and developmental combinatorial metabolomics. New Phytol. 2011, 190, 683-696.

135. Aprea, E.; Gika, H.; Carlin, S.; Theodoridis, G.; Vrhovsek, U.; Mattivi, F. Metabolite profiling on apple volatile content based on solid phase microextraction and gas-chromatography time of flight mass spectrometry. J. Chromatogr. A 2011, 1218, 4517-4524. 
136. Risticevic, S.; Deell, J.R.; Pawliszyn, J. Solid phase microextraction coupled with comprehensive two-dimensional gas chromatography-time-of-flight mass spectrometry for high-resolution metabolite profiling in apples: Implementation of structured separations for optimization of sample preparation procedure in complex samples. J. Chromatogr. A 2012, 1251, 208-218.

137. Schwieterman, M.L.; Colquhoun, T.A.; Jaworski, E.A.; Bartoshuk, L.M.; Gilbert, J.L.; Tieman, D.M.; Odabasi, A.Z.; Moskowitz, H.R.; Folta, K.M.; Klee, H.J.; et al. Strawberry flavor: Diverse chemical compositions, a seasonal influence, and effects on sensory perception. PLoS One 2014, 9, e88446.

138. Inui, T.; Tsuchiya, F.; Ishimaru, M.; Oka, K.; Komura, H. Different beers with different hops. Relevant compounds for their aroma characteristics. J. Agric. Food Chem. 2013, 61, 4758-4764.

139. Keeling, C.I.; Bohlmann, J. Genes, enzymes and chemicals of terpenoid diversity in the constitutive and induced defence of conifers against insects and pathogens. New Phytol. 2006, $170,657-675$.

140. O'Grady, J.; Schwender, J.; Shachar-Hill, Y.; Morgan, J.A. Metabolic cartography: Experimental quantification of metabolic fluxes from isotopic labelling studies. J. Exp. Bot. 2012, 63, 2293-2308.

141. Boatright, J.; Negre, F.; Chen, X.; Kish, C.M.; Wood, B.; Peel, G.; Orlova, I.; Gang, D.; Rhodes, D.; Dudareva, N. Understanding in vivo benzenoid metabolism in petunia petal tissue. Plant Physiol. 2004, 135, 1993-2011.

142. Sugimoto, K.; Matsui, K.; Iijima, Y.; Akakabe, Y.; Muramoto, S.; Ozawa, R.; Uefune, M.; Sasaki, R.; Alamgir, K.M.; Akitake, S.; et al. Intake and transformation to a glycoside of (Z)-3-hexenol from infested neighbors reveals a mode of plant odor reception and defense. Proc. Natl. Acad. Sci. USA 2014, 111, 7144-7149.

143. Oka, N.; Ohki, M.; Ikegami, A.; Sakata, K.; Watanabe, N. First isolation of geranyl disaccharide glycosides as aroma precursors from rose flowers. Nat. Prod. Lett. 1997, 10, 187-192.

144. Winterhalter, P.; Knapp, H.; Straubinger, M. Water soluble aroma precursors. In Flavor Chemistry: Thirty Years of Progress; Teranishi, R., Wick, E., Hornstein, I., Eds.; Kluwer Academic/Plenum Publishers: New York, NY, USA, 1999; pp. 255-264.

145. Wang, D.; Yoshimura, T.; Kubota, K.; Kobayashi, A. Analysis of glycosidically bound aroma precursors in tea leaves. 1. Qualitative and quantitative analyses of glycosides with aglycons as aroma compounds. J. Agric. Food Chem. 2000, 48, 5411-5418.

146. Francis, I.L.; Kassara, S.; Noble Ann, C.; Williams Patrick, J. The contribution of glycoside precursors to cabernet sauvignon and merlot aroma. In Chemistry of Wine Flavor; American Chemical Society: Washington, DC, USA., 1998; Volume 714, pp. 13-30.

147. Buttery, R.G.; Takeoka, G.; Teranishi, R.; Ling, L.C. Tomato aroma components: Identification of glycoside hydrolysis volatiles. J. Agric. Food Chem. 1990, 38, 2050-2053.

148. Sarry, J.-E.; Günata, Z. Plant and microbial glycoside hydrolases: Volatile release from glycosidic aroma precursors. Food Chem. 2004, 87, 509-521.

149. Tikunov, Y.M.; de Vos, R.C.H.; Paramas, A.M.G.; Hall, R.D.; Bovy, A.G. A role for differential glycoconjugation in the emission of phenylpropanoid volatiles from tomato fruit discovered using a metabolic data fusion approach. Plant Physiol. 2010, 152, 55-70. 
150. Schweiger, R.; Heise, A.M.; Persicke, M.; MÜLler, C. Interactions between the jasmonic and salicylic acid pathway modulate the plant metabolome and affect herbivores of different feeding types. Plant Cell Environ. 2014, 37, 1574-1585.

151. Dudareva, N.; Pichersky, E. Metabolic engineering of plant volatiles. Curr. Opin. Biotechnol. 2008, 19, 181-189.

152. Pongsuwan, W.; Fukusaki, E.; Bamba, T.; Yonetani, T.; Yamahara, T.; Kobayashi, A. Prediction of japanese green tea ranking by gas chromatography/mass spectrometry-based hydrophilic metabolite fingerprinting. J. Agric. Food Chem. 2007, 55, 231-236.

(C) 2014 by the authors; licensee MDPI, Basel, Switzerland. This article is an open access article distributed under the terms and conditions of the Creative Commons Attribution license (http://creativecommons.org/licenses/by/3.0/). 